\title{
Choosing Models to Explore Financial Supply Chain Relationships (Extended Abstract)
}

\author{
Margret Bjarnadottir \\ University of Maryland \\ margret@rhsmith.umd.edu
}

\author{
Aaron Hunt \\ University of Maryland \\ ahunt@terpmail.umd.edu
}

\author{
Louiqa Raschid \\ University of Maryland \\ louiqa@umiacs.umd.edu
}

ACM Reference Format:

Margret Bjarnadottir, Aaron Hunt, and Louiqa Raschid. 2018. Choosing Models to Explore Financial Supply Chain Relationships (Extended Abstract). In DSMM'18: Data Science for MacroModeling with Financial and Economic Datasets, June 15, 2018, Houston, TX, USA. ACM, New York, NY, USA, 4 pages. https: //doi.org/10.1145/3220547.3220552

\section{INTRODUCTION}

A residential mortgage-backed security resMBS, is a complex financial product that is constructed by pooling cash flows from a collection of mortgage loans. Figure 1 shows a simplified view of the complex product structure, composed of tranches (slices) of securities, on the right, with a prioritized waterfall payment structure. The cash flows from the pool of mortgages, on the left, both the principal and interest payments, are allocated to the securities based on the waterfall payment priority. The tranches served first are referred to as senior debt, or Class _A_ or _B_ securities, followed by mezzanine and then unsecured or equity debt. The securities are rated for their credit worthiness and are packaged within a prospectus that is issued, with the securities sold to investors. These products can be issued by government sponsored enterprises (GSEs such as Fannie Mae) or they may be issued as private label securities.

In the early $2000 \mathrm{~s}$, there was a boom in the issuance of private label resMBS products, which reached its peak around 2006, followed by a sharp decline in late 2007 and 2008. Following a housing bubble of 2007, housing prices began to decline sharply, leading to mortgage defaults, foreclosures and housing short-sales. This change in housing prices and mortgage status, coupled with a high rate of subprime lending prior to 2007, and an increase in speculative purchases, led to large losses for multiple financial institutions and investors holding these resMBS products.

Following the 2008 financial crisis, there has been much research around private label resMBS products. Researchers have investigated their performance from different angles,

Permission to make digital or hard copies of all or part of this work for personal or classroom use is granted without fee provided that copies are not made or distributed for profit or commercial advantage and that copies bear this notice and the full citation on the first page. Copyrights for components of this work owned by others than ACM must be honored. Abstracting with credit is permitted. To copy otherwise, or republish, to post on servers or to redistribute to lists, requires prior specific permission and/or a fee. Request permissions from permissions@acm.org.

DSMM'18, June 15, 2018, Houston, TX, USA

(C) 2018 Association for Computing Machinery.

ACM ISBN 978-1-4503-5883-5/18/06 . .\$15.00

https://doi.org/10.1145/3220547.3220552

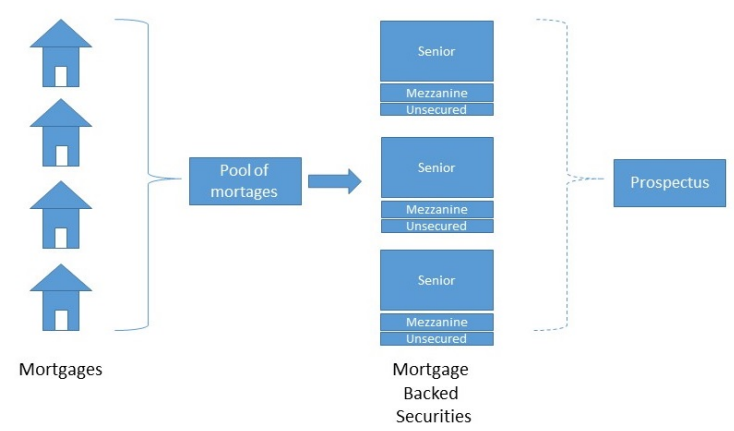

Figure 1: Simplified overview of resMBSs.

including focusing on the variation in their credit rating over time [1], the effect of issuers size on both initial prices [8] and ratings [7], and the role of accounting rules on resMBS sales[9]. In contrast, our research has a focus on financial institutions and their role(s) in the supply chain. There has been limited prior research on the supply chain. A single study [5] focuses on the effect when a particular financial institution is both an originator of mortgages, as well as either a sponsor or a servicer; in these cases, the default rates are found to be significantly lower. In our research, we use advanced text extraction and mining approaches to construct a unique and rich dataset of the supply chain. We then use probabilistic topic models to analyze the actions of financial institutions, how they build communities, and the impact of upstream communities on their downstream performance, in particular, the failure of securities to make payments.

\section{DATASETS AND FEATURES}

The resMBS dataset includes approximately five thousand prospectuses that were issued by private labels and filed with the Securities and Exchange Commission (SEC) between 2001 and 2008.

Financial entities (FEs) take on multiple roles within the upstream supply chain, including the following: issuer, originator, seller, trustee, servicer, depositor, sponsor, swap counterparty, insurer and underwriter. Each prospectus will be associated with a supply chain composed of a set of (Role, FE) pairs, e.g., (Issuer, Wachovia) and (Originator, National City). We used the IBM SystemT text analytics platform to extract the mentions of financial entities, and the role(s) that they play in the supply chain for each prospectus. The most common role extracted was servicer, followed by depositor, 
trustee and issuer. Originator and sponsor are also commonly found roles.

The next step in creating the data set was to match each prospectus with the set of associated securities. Each security has a unique identifier [4] but these CUSIP values are not included in the prospectus. We performed a search using the name of the issuing entity for each resMBS prospectus against the names of mortgage backed securities in Bloomberg [3]; when the match retrieved multiple entries, we had a human select the correct matching entry.

The features for each security include the class or tranche type, the initial principal, the maturity date for the loan, initial ratings by Moody, and additional characteristics such as the interest rate, and whether the underlying security is interest only. Each security is also associated with downstream historical payment information, includeing the original mortgage amount, the current balance, the sum of principal paid, as well as shortfall information. We developed simple heuristics based on the past payment histories to label the financial performance of each security. The labels range from Meets expectation (ME) to Fails expectation (FE). The highest performing securities, ME, made all payments on time, with no payment shortfall, and have either paid off their entire principal, or are currently making payments. The lowest performing securities, FE, had stopped making payments, prior to at least $95 \%$ of the principal being paid off. In addition Intrest Only securities were labelled as FE if they had a history of shortfall.

We consider a subset of 189 prospectuses issued in 2002, containing 2770 securities, and 268 prospectuses issued in 2006, containing 4021 securities. Figure 2 shows the distribution of labels, by year, for the class A and B securities. From Figure 2, we note that while none of the 2002 class A securities fail expectations, close to $10 \%$ of the 2006 class A securities fail expectations. As a result, if one would use the year as the only predictor in a prediction model, one can achieve a $100 \%$ accuracy on the 2002 sample. We further note that the senior secured A class of securities were the most credit worthy and were not expected to fail expectations. We also note that $14 \%$ of the 2002 class B securites fail expectations, while over $90 \%$ of 2006 class B fail expectations.

\section{MODELS AND SUMMARY OF RESULTS}

In this extended abstract, we summarize our model results. We start with regularized logistic regression with the objective of predicting the label of $\mathrm{FE}$ for the classes of $\mathrm{A}$ and $\mathrm{B}$ securities. This model will use a combination of features from the securities and the supply chain; we report on the benefits of including supply chain features. We then summarize results from applying a topic model to identify communities and model each prospectus as a mix over these hidden communities. We then use k-means clustering over the communities to determine if the upstream communities are correlated with downstream performance.

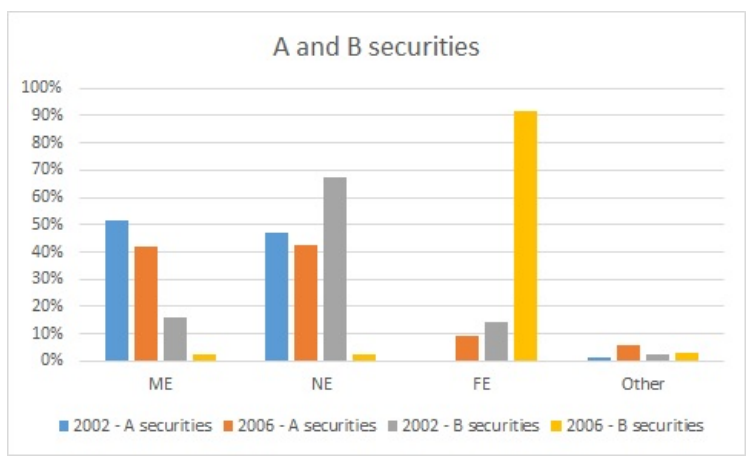

Figure 2: A histogram of the labels reflecting the performance of securities, by year. ME: Meeting expectations; NME: Not meeting expectations; FE: Fails expectations.

\subsection{Logistic Regression}

We run regularized Logistic Regression models, LASSO [6], with a binary indicator variable for whether or not a security fails expectations as the dependent variable. We train the model using information about all securities, but report the classification performance on the A and B securities. We train three different models. First, we use information about whether or not specific financial entities are associated with the prospectus. Next, we use the securities properties known at issuance to predict whether or not a security will fail expectations. Finally, we use a combined model, with both information about the presence of financial entities, as well as properties associated with each security.

Table 1 summarizes the performance of the three models by year and type, for the $2002 \mathrm{~B}$ securities and the $2006 \mathrm{~A}$ and B securities. The cut-off is held at the default value of 0.5 . Each of the models classifies 2002 A securities with almost $100 \%$ accuracy. The results for the other securites is mixed. We note that for the 2006 A securites, using the securities' properties alone achieves higher accuracy, compared to using information on the presence of financial entities alone. However, for the 2006 B securities the story is not as simple, and we note that using information on financial entities alone outperforms using information on the securities' properties alone. This is in large part driven by financial entities that are only associated with securities in 2006 . When we combine information on financial entities with a model built on securities' properties alone, there is a (small) jump in accuracy and other performance measures. Thus, additional information about the presence of financial entities associated with a prospectus can imporove a model, compared to only using the properties of the securities themselves.

Beyond accuracy and the F1-score, we specifically analyze which financial entities are associated with securities being significantly more or less likely to be labelled as failing expectations. We note, that simply looking at the regression coefficients of the financial entities may be misleading. For example, we know that the failure rate of 2002 securities is 


\begin{tabular}{|l|c|c|c|}
\hline \multicolumn{4}{|c|}{ Accuracy (\%) } \\
\hline Model & $2002 \mathrm{~B}$ & $2006 \mathrm{~A}$ & $2006 \mathrm{~B}$ \\
\hline FinE & 83.3 & 52.6 & 73.3 \\
Properties & 82.0 & 93.7 & 69.6 \\
FinE \& Properties & 85.3 & 95.1 & 94.6 \\
\hline \hline \multicolumn{4}{|c|}{ Sensitivity (\%) } \\
\hline Model & $2002 \mathrm{~B}$ & $2006 \mathrm{~A}$ & $2006 \mathrm{~B}$ \\
\hline FinE & 0 & 63.5 & 75.8 \\
Properties & 13.5 & 54.7 & 72.2 \\
FinE \& Properties & 17.4 & 68.2 & 98.5 \\
\hline \hline \multicolumn{4}{|c|}{ F1 score } \\
\hline Model & $2002 \mathrm{~B}$ & $2006 \mathrm{~A}$ & $2006 \mathrm{~B}$ \\
\hline FinE & - & 0.200 & 0.839 \\
Properties & 0.177 & 0.618 & 0.814 \\
FinE \& Properties & 0.254 & 0.721 & 0.971 \\
\hline
\end{tabular}

Table 1: Performance Summary of the Logistic Regression Models. The LR models using information on financial enteties only do not label any 2002 securities as FE, and therefore the sensitivity is 0 and the F1 score not defined.

zero, while it is close to $10 \%$ in 2006 . Therefore, if a financial entity is primarily associated with prospectuses in 2002, any model that has information on the presence of financial entities could exploit this knowledge.

Most financial institutions which are associated with large increases in the risk of failing expectations are almost or only associated with prospectuses from 2006. These include for example AMNET, Novastar, Litton Loan Servicing LP, Carrin Agreement General and Weyerhaeuser Mortgage Company. An example of a company that is associated with an increased risk of failing expectations, and is linked with prospectuses in both 2002 and 2006 (26 and 74\% respectively) is EMC Mortgage.

We further analyzed the results of the models using the securities' properties. Some of the factors that contribute to increased odds of $\mathrm{FE}$ are not suprisingly indicators of a security whose principal and/or interest distributions are subordinate to a senior structure (either subordinate or mezzanine), of the security being a stepped rate bond as well as an indicator of the the initial Moody rating being NR or "not rated".

\subsection{LDA Topic Modeling}

To gain further insights into the roles and the behavior of financial entities in the supply chain we adopt topic modeling $[2,10]$. Traditionally, documents are considered to be collections of keywords. Each topic is a distribution over these keywords, and then each document is a mix over these topics. In our model, prospectuses are collections of pairs of (Role, Financial entity) and a topic is a distribution over the (Role, Financial entity) pairs. One of the advantages of this model is that a financial entity (in a specific role) can occur in multiple communities, or in a single community, as appropriate.
Prior to running the analysis, we eliminated financial entities that appear in less than 20 prospectuses, and we eliminated prospectuses that contain less than three financial entities or five (Role, Financial entity) pairs.

We used prospectuses from 2002 through 2005 to generate the communities, and evaluated the generated topics using prospectuses from 2006 through 2008. The resulting topic models were evaluated using a perplexity metric as well as a coherence metric. The perplexity scores reflect that the models produce topics that can generate the contents of the unseen prospectuses with reasonable accuracy. The coherence scores reflect that the topics are a good agreement with the prospectuses. Interestingly over $25 \%$ of the prospectuses fall within a single topic (defined as having a topic weight ¿.95) and close to $70 \%$ of the prospectuses have a dominant topic (defined as having a topic weight i.5).

Examples of communities include the Bank of America, Banc of America Securities LLC, Wells Fargo, Cendant Mortgage and Asset Backed Funding. Another example of a community is the set of Countrywide Home Loans, Countrywide Securities Corporation, Bank of New York Mellon Corp, Wilmington Trust and J.P. Morgan Chase. An example of a community of financial entities playing specific roles is the following: Countrywide Securities Corporation as a depositor, Countrywide Home Loans as a master servicer and a seller, Wells Fargo as a seller and the Bank of New York Mellon Corp as the trustee.

Beyond statistical validation we also analyzed whether topic models could be applied to identify toxic communities, i.e., communities associated with many failed financial entities. We focus on models of (Role, Financial entity) pairs. We have observed from anecdotal evidence that communities with toxic entities in certain roles are more likely to impact the performance of securities. We first created a smaller dataset with higher quality, and then applied many additional tuning steps to achieve satisfactory results.

Examples of toxic communities include one with Indymac playing multiple roles (servicer, seller, depositor and issuer) with Deutche Bank as the trustee. A second community has National City as the originator and servicer, First Franklin Financial Corp as the issuer, and Bank of America and HSBC as originators. We refer the reader to https://dsfin. umiacs.umd.edu/topicmodels/resMBS/ for visualizations of the topic models.

\subsection{K-means Clustering}

In order to investigate the potential of topic models as a foundation for grouping of failing securities we ran K-means clustering on the same dataset as was used for the logistic regression models. We hypothesize that certain toxic financial communities are more strongly connected to toxic securities; thus, by grouping prospectuses together based on their affiliations with various communities, we may be able to identify clusters of varying toxicity as reflected by their failure rate of securities. 
The clustering analysis was run using the topic weights of each prospectus as the independent variables; we experiments with various values for $k$, but report on the results when $k=20$. When analyzing the resulting clusters, we note a wide range of cluster behavior. For example, we note multiple clusters where no securities fail expectations. We provide two examples of clusters with high failure rates. The cluster with the highest failure rate, $68 \%$ is a cluster containing 200 securities, out of which 136 securities failed expectations. This cluster is contains prospectuses associated with two financial communites (topics). First a partially toxic community of Bear Sterns \& Co. Inc. as the issuer and depositor, Encore Credit Corporation as the originator and EMC Mortgage as the servicer and seller. Second a toxic financial community that consists of INDYMAC, Olympus Servicing L.P, and Weyerhaeuser Mortgage Company as originators, and Ameriquest Mortage Co. as a seller and servicer. The second example is a cluster of 48 securities with an elevated failure rate of almost $40 \%$. This is also a toxic community with Weyerhauser Mortgage Corp as originator, American Home Mortgage as issuer, servicer and depositor, and Wells Fargo as trustee.

Our initial exploration has thus identified that upstream toxic financial communities may indeed impact downstream financial performance, and failure, of the assocaited securities.

\section{CONCLUSION AND FUTURE WORK}

This preliminary research has shown the importance of the financial entities, their roles, and the supply chain, on the performance of resMBS securities, in the years leading up to the US financial crisis in 2008. We have shown that information about financial entities involved in the issuance and sales of resMBS offers information about the probability of failure, and that toxic securities, defined as securities failing to meet expectations, are prominent in toxic financial communities. In this work we have specifically focused on prospectuses issued in 2002 and 2006, and significant work lies ahead in extending the analysis to cover the years from the time private label resMBSs became popular until the financial crash in 2008. The models and results presented above provide a first step in fully understanding the role of financial entities and their self organization in the resMBS supply chain and the results indicate that financial entities and their roles behind resMBSs are worth a detailed examination.

\section{ACKNOWLEDGMENTS}

This research was partially supported by NIST award 70NANB15H194 and NSF grants CNS1305368 and DBI1147144 and the Smith School of Business.

\section{REFERENCES}

[1] Adam Ashcraft, Paul Goldsmith-Pinkham, and James Vickery. 2010. MBS Ratings and the Mortgage Credit Boom. Federal Reserve Bank of New York Staff Reports, no. 449 (2010).

[2] D Blei, A Ng, and M Jordan. 2003. Latent dirichlet allocation. Journal of Machine Learning Research 3 (2003), 993-1022.

[3] Bloomberg 2017. Bloomberg L.P. https://en.wikipedia.org/wiki/ Bloomberg_Terminal.
[4] CUSIP [n. d.]. Cusip global services. https://www.cusip.com/ cusip/index.htm.

[5] Cem Demiroglu and Christopher James. 2012. How Important is Having Skin in the Game? Originator-Sponsor Affiliation and Losses on Mortgage-backed Securities. The Review of Financial Studies 25 (2012), 3217-3258.

[6] Trevor Hastie, Robert Tibshirani, and Jerome Friedman. 2009. The Elements of Statistical Learning: Data Mining, Inference, and Prediction (2nd. ed.). Springer.

[7] Jie He, Jun Qian, and Philip E. Strahan. 2011. Credit Ratings and the Evolution of the Mortgage-Backed Securities Market. American Economic Review 101 (2011), 131-35.

[8] Jie He, Jun Qian, and Philip E. Strahan. 2012. Are All Ratings Created Equal? The Impact of Issuer Size on the Pricing of Mortgage-Backed Securities. The Journal of Finance 67 (2012), 2097-2137.

[9] Craig B. Merrill, Taylor D. Nadauld, Ren M. Stulz, and Shane Sherlund. 2012. Did Capital Requirements and Fair Value Accounting Spark Fire Sales in Distressed Mortgage-Backed Securities? NBER Working Paper No. 18270 (2012).

[10] M Steyvers and T Griffiths. 2007. Probabilistic topic models. Laurence Erlbaum. 